\title{
Computational apprenticeship: Cognitive apprenticeship for the digital era
}

\author{
Hayden Fennell ${ }^{1}$, Joseph Lyon ${ }^{2}$, Aasakiran Madamanchi ${ }^{1}$, Alejandra J. Magana ${ }^{1}$ \\ Submitted to: Theory and Research in Education September 2019
}

\begin{abstract}
The conceptualization of Computational Thinking as a cross-cutting skill with relevance across disciplines has ushered in wide-ranging efforts to increase computational education in all facets of education. However, the majority of initiatives for integrated computing education have focused on K-12 settings, as has most education research around computational thinking. At the postsecondary level, computing education remains largely siloed within specific programming courses and has not been well-integrated throughout the STEM curriculum. Current instructional approaches often leave students poorly prepared to transfer their computing knowledge to solve new real-world problems. Additionally, there is limited education research into how best to develop computational thinking among postsecondary students. In fact, education research into computational thinking remains undertheorized and is often definitional in nature. Here, we integrate computational thinking with the educational psychology concept of adaptive expertise. Finally, we contextualize computational thinking within constructivist learning theories by introducing computational apprenticeship, an application of cognitive apprenticeship to computing. Computational apprenticeship provides a research and practice model for supporting the development of computational adaptive expertise.
\end{abstract}

1 Department of Computer and Information Technology, Purdue University, 401 N. Grant Street, West Lafayette, IN 47907, USA

2 School of Engineering Education, Purdue University, 701 W. Stadium Ave, West Lafayette, IN 47907, USA

* This material is based upon work supported by the National Science Foundation Graduate Research Fellowship Program under Grant No. (DGE-1842166) as well as the National Science Foundation under Grant No. (EEC-1449238). Any opinions, findings, and conclusions or recommendations expressed in this material are those of the authors and do not necessarily reflect the views of the National Science Foundation. 


\section{Introduction}

Jeanette Wing's 2006 articulation of Computational Thinking (CT) positioned computing as a foundational approach to the digital world, rather than a specific discipline within it. This paradigm has captured the attention of policymakers, educators and industry groups who increasingly recognize computing as a critical workforce skills for national security and economic competitiveness needs (PITAC, 2005). In recent years computational thinking has been central in national education reform initiatives including Next Generation Science Standards and CS4ALL ([NRC], 2013; [USOPS], 2016).

In contrast to the focus on integrated computing education in K-12 settings, innovation in computing education at the postsecondary level has lagged behind (Kalelioğlu, Gülbahar, $\&$ Kukul, 2016). At the postsecondary level, computing remains largely siloed within certain programming specific courses rather than combined with disciplinary materials due to lack of space in the curriculum as well as lack of student knowledge (Magana, Falk, \& Reese Jr., 2013; Magana \& Silva Coutinho, 2017). At the same time, the majority of research on computational thinking, from both academic and industry sources, remains highly definitional in nature ([NRC], 2011; CollegeBoard, 2013; Google, 2015; Grover \& Pea, 2013; Kalelioğlu et al., 2016). To date there has been limited empirical study of how best to support computational thinking development in undergraduates (Kalelioğlu et al., 2016). As a result, current practice in computation education focuses heavily on the procedural and technical aspects of programming knowledge and on learning specific programming languages (Buitrago Flórez et al., 2017; Pears et al., 2018; Vihavainen, Airaksinen, \& Watson, 2014). These traditional instructional approaches often provide students with 'near' transfer but not 'far' transfer capabilities. Students are, therefore, left with the ability to apply known solutions to common problems in the discipline but without the ability to adapt to new challenges in the real-world (Butler \& Morgan, 2007). Limited 'far' transfer ability has been identified in the computational and data science abilities of professional scientists and engineers (Heroux \& Allen, 2016; Madamanchi, Cardella, Glazier, \& Umulis, 2019).

In recent years there has been growing recognition of the limitations of current computational education approaches ([NRC], 2011; PITAC, 2005) and the need for computational pedagogy in STEM disciplines that emphasizes discipline-based computational problem solving processes (Dym, 2004; Magana et al., 2013). In this paper, we introduce computational adaptive expertise to contextualize the challenge of developing 'far' transfer computational abilities with the broader educational psychology expertise research. Additionally, we propose computational apprenticeship, an application of cognitive apprenticeship to discipline-based computing education, as a research and practice model for the development of computational adaptive expertise. In doing so, the framework brings constructivist learning into discipline-based computing education.

\section{Adaptive Expertise}

The education psychology concept of adaptive expertise was first proposed by Hatano and Inagaki (1986) in their work with Japanese school children. Hatano and Inagaki proposed that students fall into "two courses of expertise" as they learn and grow: routine 
expertise and adaptive expertise. Routine expertise is often characterized as being defined by procedural knowledge, in which an individual develops efficient skill in a task through long-term repetition and practice. Adaptive expertise is characterized more generally by conceptual understanding (Bransford, Brown, \& Cocking, 2000) and by the ability to learn skills in a way that allows them to be transferred between contexts. In other words, adaptive experts have the ability to quickly become accustomed to changes in their discipline or work requirements (G Hatano \& Inagaki, 1986).

In this way, adaptive and routine expertise are often depicted as two branching "paths" of expertise, with routine expertise being driven largely by the refinement of procedural knowledge and adaptive expertise being driven largely by the acquisition of transferable conceptual knowledge. However, recent work and thinking in the field have indicated that routine and adaptive expertise exist along the same continuum of development, and that adaptive expertise is built on a foundation of at least some level of routine expertise (Bohle Carbonell, Stalmeijer, Könings, Segers, \& van Merriënboer, 2014; Giyoo Hatano \& Oura, 2003; Schwartz, Bransford, \& Sears, 2005). In other words, all adaptive experts must first become routine experts in their field or practice to some degree. Therefore, rather than being driven primarily by conceptual knowledge, adaptive expertise is a combination of procedural knowledge, conceptual knowledge, and the ability to transfer that body of knowledge to new applications (Bransford et al., 2000). This idea of balancing knowledge and skills is further elaborated upon by Schwartz et al. (2005) in their two-dimensional model of adaptive expertise. This model conceptualizes adaptive expertise as a balance of innovation and efficiency, as shown in Figure 1.

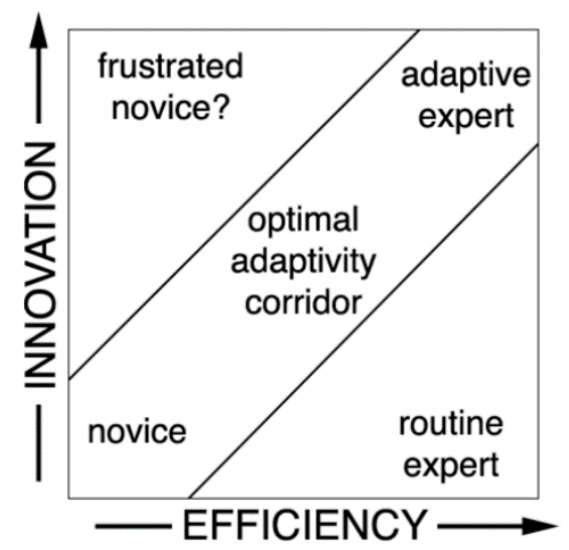

Figure 1. The development of adaptive expertise through both innovation and efficiency (Schwartz et al., 2005).

Efficiency is the ability to "rapidly retrieve and accurately apply appropriate knowledge and skills to solve a problem or understand an explanation." (Schwartz et al., 2005, p. 28). Innovation, on the other hand, is the ability to create new solutions to problems by altering, modifying, or building upon existing knowledge (and sometimes even creating new knowledge in the process). Efficiency is important in many domains, particularly in high-production corporations, manufacturing companies, and in many medical positions such as specialized surgeons. However, a strong focus on developing efficiency often comes at a cost to innovation, as strategies and skills become more familiar and more 
narrowly applicable to common problems. On the other hand, an over-focus on innovation can also negatively impact efficiency, as lack of design constraints and too much time spent on any one problem may lead to frustration and/or avoidable financial risks during a project. Schwartz, Bransford, and Sears (2005) propose a new method of thinking about the efficiency/innovation balance by proposing an "optimal adaptability corridor" that learners should be assisted in navigating during university or other training programs. Curricula designed with this adaptability corridor in mind would give students ample time to participate in activities that allow them to work on both sharpening their routine efficiency and flexing their adaptive innovation skills and strategies, with the goal of producing more prepared adaptive experts who are ready to transfer their knowledge into the workforce. With this in mind, three sets of "expertise trajectories" can be applied to the innovation vs efficiency model, as shown in Figure 2.

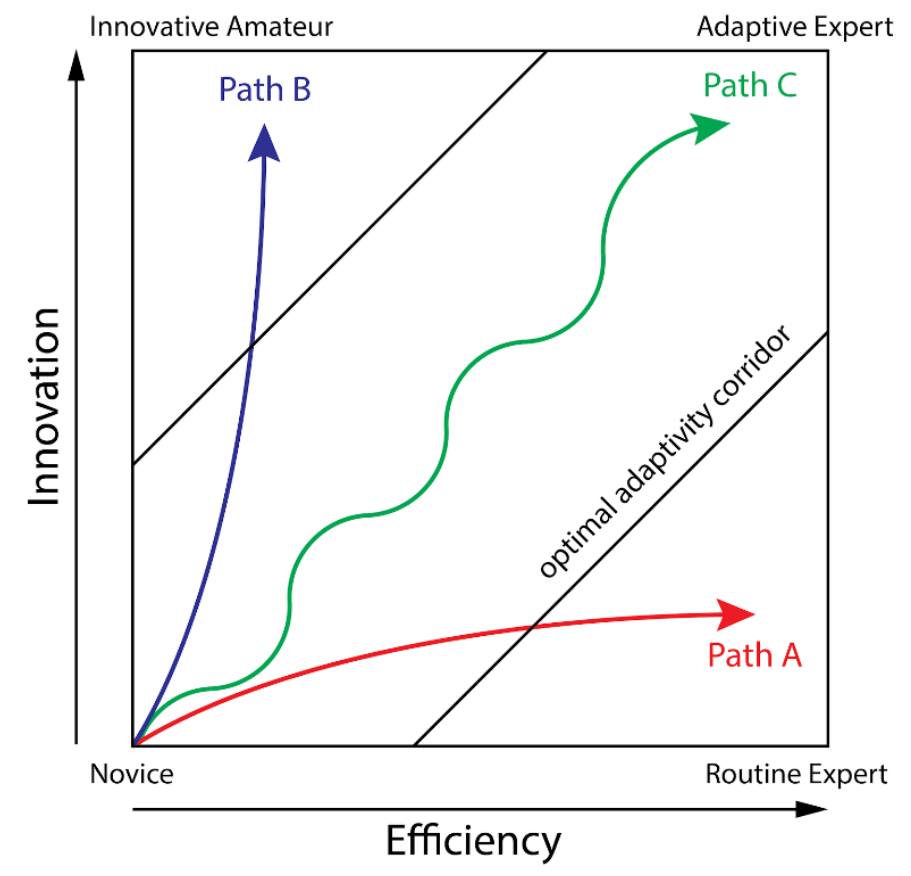

Figure 2. Three trajectories within the expertise model.

Trajectory A represents a situation in which too much focus is placed on efficiency and procedural knowledge. This trajectory tends to send students out of the optimal adaptivity corridor and produce routine experts. Although routine expertise is useful in many fields and is the cornerstone of adaptive expertise, it also risks producing a form of "cognitive entrenchment" in the learner (Dane, 2010), in which the currently effective knowledge and methods are viewed as the "best" methods and adopting new approaches becomes difficult. Trajectory $\mathrm{B}$ represents a situation where too much focus is placed on innovation and self-directed learning. This trajectory is similar to trajectory A in that it sends students out of the optimal adaptivity corridor, but in the opposite direction, resulting in what we are referring to here as an "innovative amateur." These learners are able to devise creative conceptual solutions to new problems, but ultimately struggle to implement those solutions effectively due to a lack of procedural expertise. The optimal 
trajectory, then, would be Trajectory $\mathrm{C}$, where innovation and self-directed learning are balanced by expert guidance about efficient strategies and useful procedural knowledge. Therefore, the goal of a program focused on the development of adaptive expertise should seek to balance a combination of innovation-oriented and efficiency-oriented constructivist learning activities in order to keep students aligned with trajectory C. How to do this can be a complicated and involved process, however, as the methods by which learners acquire expertise are still unclear.

In the context of computational thinking, STEM education has typically focused on teaching the technical and more cognitive aspects of computation and computational thinking. Constructivist teaching approaches are underutilized but potentially powerful in computational contexts (Ben-Ari, 1998; Thevathayan \& Hamilton, 2015). Rather than trying to create or structure pedagogy so that it specifically builds CT skills, computational thinking can be fostered by giving students pedagogy that allows them to construct knowledge and skills from their own experiences. A constructivist teaching approach when dealing with computational thinking would allow students to learn these skills in a way in which they are embedded in real-world context and experiences. This need for authentic constructive learning experiences that can promote the development of adaptive expertise within computation leads to a need for new pedagogies and instructional methods for incorporating computation and computational thinking skills into the classroom. As opposed to teaching computation and computational thinking in an abstract, non-grounded way, skills associated with computational thinking can be anchored and made visible through real-world situations and problem-solving. Table 1 outlines the various components of computational thinking and the associated definitions.

Table 1

Definitions of computational thinking as adapted from Curzon et al. (2014).

\begin{tabular}{|c|c|}
\hline Skill & Definitions \\
\hline Abstraction & $\begin{array}{l}\text { The ability to simplify complex problems so that they are easier } \\
\text { to solve. }\end{array}$ \\
\hline $\begin{array}{l}\text { Algorithmic } \\
\text { Thinking }\end{array}$ & The ability to produce a solution using procedural steps. \\
\hline Evaluation & $\begin{array}{l}\text { The ability to make sure that solutions are accurate, reasonable, } \\
\text { or needed. }\end{array}$ \\
\hline Generalization & $\begin{array}{l}\text { The ability to use previous strategies for current problems, or } \\
\text { current strategies for future problems. }\end{array}$ \\
\hline Decomposition & $\begin{array}{l}\text { The ability to break down complex problems and solutions into } \\
\text { smaller parts. }\end{array}$ \\
\hline
\end{tabular}

By placing complicated and abstract concepts such as computational thinking within realworld situations, the implicit is made more explicit and would allow for students to make connections between the learning scenario and the world around them. One such method that allows for constructivist learning while giving students the skills needed to become computational thinking-enabled STEM professionals is the cognitive apprenticeship 
model (Collins, 2006). In this paper, we present computational apprenticeship as a reimagination of the cognitive apprenticeship model for teaching these critical computing education skills to develop the adaptive expertise needed in this rapidly changing field.

Apprenticeship models have been used to teach knowledge and skills to train expert practitioners since the beginning of written history. In many skilled trades, the apprenticeship model is still used to great effect to train individuals in the knowledge and skills needed for a trade or profession. The apprenticeship models employed by many trades and other skill-based professions are, in many ways, inherently situated in their practical context. Apprentices learn in context by observing their instructors as they engage in the practice and taking in the key features of what expert practice "looks like" in that field. The apprentices then hone their skills through a process of "legitimate peripheral participation" (Lave \& Wenger, 1991) in which learners are encouraged to put their new knowledge to practice in real-world contexts that carry significant weight within the discipline. These activities are often guided and/or monitored by the instructor, or are structured in a way that reduces or removes the risk of professional practice (i.e., peripheral), but the learner is nevertheless participating in a "real" (i.e., legitimate) component of the trade or discipline while engaged with peers and superiors within their community of practice.

This constructivist method of learning, used often in trades and other industries of skilled labor, stands in contrast to the didactic methods traditionally used in academic disciplines such as biology or engineering. These fields are often taught as a series of courses delivering a body of required background knowledge and testing students through the use of hypothetical or highly abstract pen-and-paper assessments. While pen-and-paper exams are still an effective method of assessing recall and conceptual application of content knowledge, the pedagogy surrounding these assessments often neglects the development of other important skills, critical thinking lenses, and problem-solving strategies associated with the profession. In other words, traditional "lecture and exam" structures often fail to teach students how to think like a practitioner in their discipline.

Collins et al. (1987) proposed a framework for adapting the apprenticeship method to teaching cognitive skills within modern academic topics. Known simply as Cognitive Apprenticeship, this framework has since been more formalized into a constructivist pedagogical design tool for teaching complex topics both in STEM fields and in other areas of study. The Cognitive Apprenticeship framework breaks the design of a given learning environment into four key dimensions: content, method, sequencing, and sociology. Each of these dimensions - as well as their sub-components - are briefly described in Table 1 below. Descriptions of the subcategories for each dimension can be found in Appendix A.

Table 2

Cognitive apprenticeship components with descriptions (Collins, 2006).

\section{Component Description}



Content The actual content, knowledge, and skills intended to be taught during the learner's engagement with the course or curriculum. These are broken up into domain knowledge, heuristic strategies, control strategies, and learning strategies.

Method The pedagogical approach, learning strategies, and teaching methods used to promote the development of expertise. These methods dimension consist of six components: modeling, coaching, scaffolding, articulation, reflection, and exploration.

Sequencing How activities are ordered in order to best support learning. Activities can be ordered according to increasing complexity, increasing diversity, and shifting from global to local skills.

Sociology The social characteristics of the learning environment. This includes teaching through situated learning, establishing a community of practice, promoting a community of practice, and taking advantage of cooperation.

For a more complete and detailed description of each dimension of the cognitive apprenticeship framework, including the subcategories of each of the dimensions listed in Table 2, please see Appendix A.

Due to its historical roots, cognitive apprenticeship has been most influential in laboratory or professional development contexts. The training and professional development of allied health professionals and students often use principles of cognitive apprenticeships (Lyons, McLaughlin, Khanova, \& Roth, 2017). Similarly, cognitive apprenticeship principles are frequently used in the professional development of K-12 teachers (Davis, Parker, \& Fogle, 2019; Marti \& Vegas, 2018; Peters-Burton, Merz, Ramirez, \& Saroughi, 2015), and faculty (Merritt et al., 2018). Additionally, education researchers have repeatedly used cognitive apprenticeship as an interpretive framework for understanding undergraduate and graduate research training experiences (Feldon, Shukla, \& Anne Maher, 2016; Gilmore, Vieyra, Timmerman, Feldon, \& Maher, 2015) The use of cognitive apprenticeship as an instructional approach in classroom settings has been more limited. Among the few available examples are cognitive apprenticeship based instruction interventions in chemistry and physics (Amalia, Ibnu, Widarti, \& Wuni, 2018; Subali, Rusdiana, \& Subali, 2017).

\section{A Model of Computational Apprenticeship}

With this apprenticeship framework in mind, we can begin to lay out our case for a new type of cognitive apprenticeship intended to build computational adaptive expertise. Many of the principles discussed in the cognitive apprenticeship framework can clearly be applied as described when teaching programming and other computational skills. However, the acquisition of computational adaptive expertise within the STEM disciplines in which they are now needed is a unique challenge that can be aided by the use of a new type of computation-oriented cognitive apprenticeship: a computational 
apprenticeship, for short. Here we describe the unique aspects of applying cognitive apprenticeship to the computational realm.

Computational thinking skills span a wide variety of different subjects as more and more modern disciplines rely on computational approaches. Although computation is applied differently in various fields through different standard software and different research and design goals, the core computational thinking skills remain the same across disciplines. This positions computational thinking as a highly relevant and transferable skill set in modern STEM fields. However, teaching these skills alongside already complex disciplinary material presents a number of logistical and pedagogical challenges. The solution to this concern has often been to simply separate the teaching of computational content from the disciplinary content by either isolating it in a single course within the program or outsourcing it to computer science departments, rather than spiraling computation throughout the entire curriculum (Magana et al., 2013; Magana \& Silva Coutinho, 2017). This approach to teaching programming knowledge makes learning broader computational thinking skills difficult, as the computational content is often decoupled from disciplinary practice.

The computational apprenticeship framework therefore suggests that computation be taught in context as an important disciplinary skill (Koretsky \& Magana, 2019; Alejandra J. Magana, 2017), rather than an additional kind of knowledge that is useful to have. This fits well within the cognitive apprenticeship framework, as many computational thinking skills can be "passed down" by the expert instructors in service of teaching the disciplinary material. Incorporating computational methods into STEM courses/curricula that reflect the ways that computation is actually used in practice is a key component of the computational apprenticeship model. However, this can become complicated fairly quickly, as we are essentially "doubling up" on the content dimension of the apprenticeship model by asking students to learn two fields at once: (a) the discipline that they signed up for and (b) some level of computational content and methodology (which often could be a course in and of itself (Alejandra J Magana, Brophy, \& Bodner, 2012b; Alejandra J Magana, Falk, \& Reese Jr, 2013). To account for this, we suggest that an additional content dimension be added to the framework, as seen in Table 3 . 
Table 3

Descriptions of computational content dimension subcategories.

\begin{tabular}{|c|c|c|}
\hline \multirow{4}{*}{$\begin{array}{c}\text { Computational } \\
\text { Content }\end{array}$} & Programming Knowledge & $\begin{array}{l}\text { Knowledge of programming and } \\
\text { general algorithmic design/thinking. } \\
\text { Essential coding skills not specific to a } \\
\text { particular programming language. }\end{array}$ \\
\hline & Computational Methods & $\begin{array}{l}\text { General techniques for solving } \\
\text { problems using computation. Many } \\
\text { computational methods apply to a } \\
\text { variety of disciplinary contexts. }\end{array}$ \\
\hline & Troubleshooting/Debugging & $\begin{array}{l}\text { Strategies for fixing, testing, and } \\
\text { verifying/validating code throughout a } \\
\text { computational task. }\end{array}$ \\
\hline & Learning Strategies & $\begin{array}{l}\text { Strategies for independently acquiring } \\
\text { new computational knowledge and } \\
\text { programming strategies. }\end{array}$ \\
\hline
\end{tabular}

With this new content dimension, the computational apprenticeship framework can be considered as consisting of two primary domains: (1) knowledge and skills and (2) instructional supports. The two content dimensions comprise the knowledge and skills domain while the method, sequencing, and sociology dimensions comprise the instructional supports domain (Figure 3).

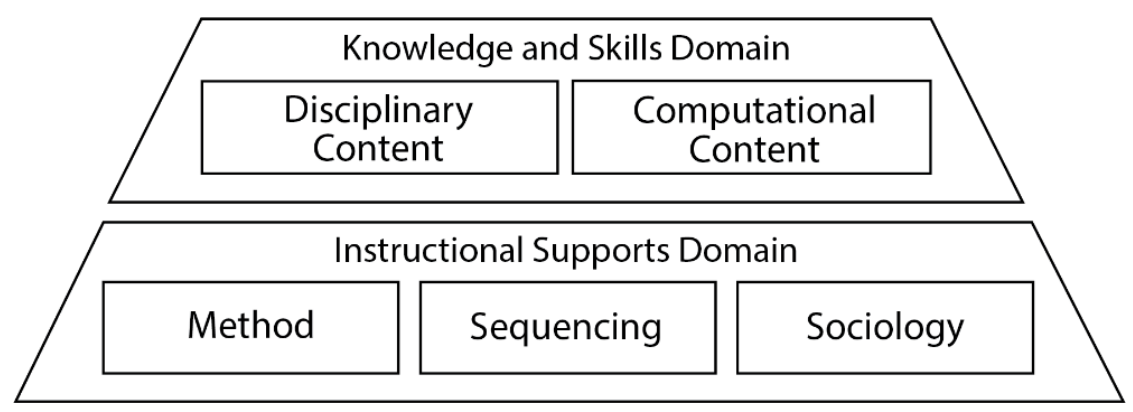

Figure 3. Overview structure of the computational apprenticeship framework

As can be seen in Figure 3, the computational apprenticeship framework forms a sort of hierarchy, with the knowledge and skills domain being founded on a base of the instructional supports domain. This represents the overall philosophy of the computational apprenticeship approach, with the two content dimensions being "built upon" the foundation of the instructional supports domain. While the exact content being 
taught will vary depending on whether a given activity focuses more on disciplinary knowledge or computational knowledge, the instructional supports domain applies equally for teaching both disciplinary and computational content throughout the learning process. In fact, the instructional supports domain acts as both a mediating factor and a unifying force between the computational and disciplinary content, as it allows for the construction of learning activities/opportunities that combine computational practice with disciplinary thinking in situated, meaningful contexts. To achieve this symbiosis between content dimensions, the computational material should be grounded in the relevant computational reasoning skills (Alejandra J. Magana, 2017; Alejandra J Magana, Brophy, $\&$ Bodner, 2012a), rather than in the specifics of programming concepts or languages (i.e., "how does computation support the learning of the disciplinary material"). This approach focuses more on generalizable (and therefore transferrable) computational thinking skills than on specific languages or extensive programming knowledge. This provides important context for the computational material as a tool to enable disciplinary practices rather than learning computation through decontextualized programming knowledge. Incorporating these computational thinking skills into disciplinary problems is an important element of modeling in the computational apprenticeship framework, as it demonstrates the use of computational methods in context as part of "thinking like an X." This is different from the currently predominant method of teaching some programming in its pure form and hoping that students will connect the dots on their own.

The computational apprenticeship framework stems in part from recent research on the incorporation of computational methods into undergraduate science and engineering course using the cognitive apprenticeship approach. Such efforts have introduced students to meaningful computational practices through a series of large scale, disciplinesituated programming projects. Elements of the cognitive apprenticeship approach were implemented as follows:

- Content: The combination of disciplinary domain knowledge with modeling and simulation practices, techniques, and tools (Joseph A. Lyon, 2019; Alejandra J Magana et al., 2013; Alejandra J Magana et al., 2017; Ortega-Alvarez, Sanchez, \& Magana, 2018)

- Method: The scaffolding approaches provided to students in the form of codesnippets, test cases, and worked-out examples (Alejandra J Magana, Falk, Vieira, \& Reese Jr, 2016; Vieira, Magana, Roy, \& Falk, 2019; Vieira, Yan, \& Magana, 2015). The course also utilized a flipped-lecture design to free up class time for more hands-on and group learning activities, which were monitored closely during class by the instructor and the TAs. Students were given extended periods of time to complete each project, allowing plenty of time for students to seek help from the instructional staff when they were stuck.

- Sequencing: Implemented by following the problem solving process as steps for guiding the modeling and simulation process (Fennell, Coutinho, Magana, D, \& Zavattieri, 2017; Alejandra J Magana et al., 2016; Shaikh, Magana, Vieira, \& Garcia, 2015).

- Sociology: Utilizing anchored instruction by contextualizing the learning experiences within authentic tasks, which occur in real-life contexts and establish meaningful associations between learning experiences and among the knowledge, 
skills, and practices of a discipline (Choi \& Hannafin, 1995; Magana, Falk, Vieira, \& Reese, 2016).

Although the students generally came into the course with a limited, novice-like ability to engage with computational tools and procedures, research on the outcomes of the course over multiple semesters has shown that this more intensive exposure to modeling and simulation methods tends to improve students' self-efficacy beliefs about their ability to use computational tools and interpret simulation data (Magana et al., 2013, 2016). After a semester in the course, students reported positive perceptions regarding their abilities to perform a wide variety of computing tasks in discipline-centered applications, such as solving a set of linear equations, representing an atomic molecular structure, solving initial and boundary value problems and implementing a numerical model, and so on. Students also reported positive perceptions surrounding their acquisition of computational concepts and procedures for solving well-structured problems. This suggests that repeated exposure to modeling and simulation techniques at the undergraduate level is an important first step in preparing students for the computational expectations of many modern engineering workplaces. However, further research in additional settings is needed to identify students' challenges in these environments, as well as the processes involved in acquiring and transferring computational skills to illstructured problems in different situations.

Closer qualitative analysis of a collection of retrospective think-aloud interviews found a connection between student's cognitive and metacognitive approaches when engaged in the modeling activities. Qualitative analysis of the students' problem-solving process as described in the interviews resulted in an outcome space of four predominant archetypes of behavior. Findings from our study identified four categories of description; two for the cognitive dimension and two for the metacognitive dimension (Magana, Fennell, Vieira, $\&$ Falk, 2019). To summarize briefly, in the cognitive dimension, the two main approaches that students adopted were implementation-oriented and knowledge-oriented. While implementation-oriented students tended to focus predominantly on writing functioning code, the knowledge-oriented students tended to focus on understanding how the disciplinary knowledge connected with the computational setup. Likewise, the metacognitive dimension also saw the adoption of two main approaches: action-oriented and plan-oriented. Action-oriented students tended to jump right into their solutions with little or no planning, while plan-oriented students tended to attempt to understand their approach in advance by planning their solution before starting to code. Each student occupied one of four problem-solving archetypes in our two-dimensional outcome space: plan/knowledge-oriented, implementation/knowledge-oriented, plan/implementationoriented, and action/implementation-oriented. A preliminary mapping of these archetypes to the adaptive expertise framework resulted in two clear and distinct patterns of student behaviors: (1) students who exhibited action/implementation-oriented behaviors were more aligned with novice approaches to expertise and (2) students who exhibited plan/knowledge-oriented behaviors were more aligned with adaptive expertise. Students with other combinations of behaviors (plan/implementation and action/knowledge) represented an intermediate state of understanding, often diverging away from the optimal adaptivity corridor as in paths A and B from Figure 2. However, further work is needed to solidify the categories as they relate to adaptive expertise behaviors, as well as 
to better understand how students of different types can be kept in the optimal adaptivity corridor throughout a computational learning activity. Further work is also needed to show how courses like CPMSE-designed using cognitive apprenticeship principlesmay be further refined according to the computational apprenticeship framework in order to help move a wider variety of students toward the more adaptive characteristics observed in the plan/knowledge-oriented archetype.

\section{Bringing Skills to Capabilities}

The ultimate goal of the computational apprenticeship model is to help learners turn the skills acquired during training into broader capabilities in future practice while they are still in training. Teaching through the apprenticeship model helps prepare students to address unfamiliar problems in the field by making the thinking and experience of experts in the discipline visible throughout the learning process. This paves the way to adaptive expertise, as practitioners who are well-prepared to apply computation in the field by thinking like an expert will be better able to address unfamiliar problems as they arise. While a skilled practitioner may be able to address common problems quickly and efficiently, a capable practitioner can both apply known skills efficiently and develop new skills as they are needed. The computational apprenticeship framework builds capability rather than just skills by providing the learner with a discipline-situated environment that reflects the knowledge structures and hands-on experience needed to turn knowledge and skills into flexible capabilities.

By facilitating carefully guided learning of practical and transferable skills, the computational apprenticeship framework helps develop more adaptive expert capabilities. The generalization of specific computational thinking skills into a wholistic set of core computational capabilities prepares the learner to address new problems in practice. The computational apprenticeship framework is useful in helping students to gradually expand the integration (and therefore usefulness) of their skill sets over time, allowing them to address more and more complex and varied problems until they are prepared to set off on their own in the workforce, academia, or other profession. This "expansion" of computational thinking abilities from isolated skills to a set of integrated capabilities is depicted in Figure 4.
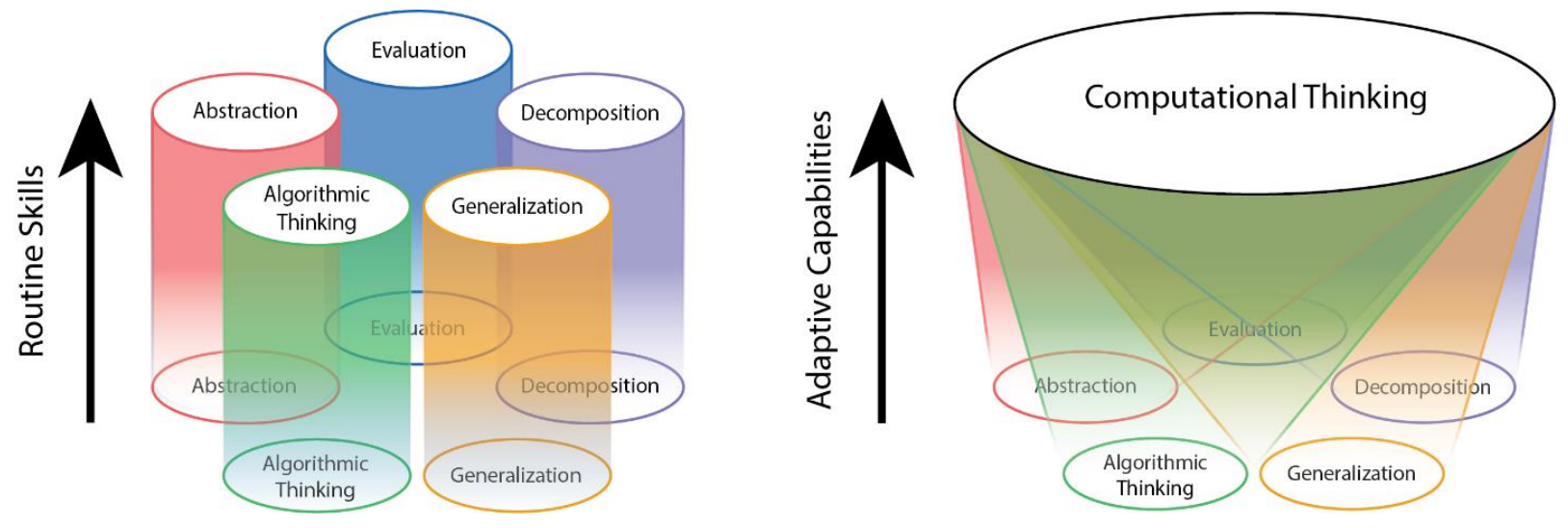
Figure 4. The development of computational thinking skills into routine, isolated skills over time (left) versus the development of an integrated, adaptive capability for computational thinking during apprenticeship (right).

The development of adaptive expertise is dependent on a balance of innovation and efficiency during the learning process. While efficiency in specific skills can be built through rote practice and repetition, the integration of skills required to form capabilities occurs when learners are forced to combine skills in new ways in order to solve unfamiliar or ill-structured problems. The computational apprenticeship framework is key in facilitating the development of computational adaptive expertise, as it provides a safe, guided environment in which students may engage in computational innovation. This allows for the broadening and combination of individual skills as the learner moves through the apprenticeship toward an adaptive capability for computational thinking. This shift toward capabilities is enabled by prioritizing the teaching of computational thinking abilities rather than pure programming skills and syntactical knowledge. While some level of programming and syntax basics will always be needed as a foundation for more sophisticated skills, the focus of computational learning activities should be centered around using computation to achieve some other disciplinary goal.

In this integrated computational apprenticeship model, then, three things must be considered when designing learning activities (Koretsky \& Magana, 2019): (1) what disciplinary material is being taught; (2) what computational/programming concepts are being taught and/or reinforced; and (3) how does the computational content support the learning of the disciplinary content (i.e., what computational thinking skills are being incorporated)? These first two points represent the "doubling up" of the cognitive apprenticeship framework in computational learning activities, but it is the third point that is often overlooked. Teaching two things at once is easy enough to imagine, but teaching disciplinary and computational content together in a way in which one actively supports the learning of the other is more challenging.

However, computational thinking can be taught using an apprenticeship model much in the same way that any other body of knowledge can. Design of computational learning activities under the computational apprenticeship model should consider the following design questions:

1. What disciplinary content is this activity addressing?

2. What programming knowledge or computational method is this activity addressing?

3. Which computational thinking skills is this activity teaching or reinforcing?

4. How does the computational content contribute to the disciplinary material? Is that contribution meaningful enough to justify the added complexity?

5. What scaffolding and social supports will students need to meet the learning objectives of the activity?

6. Is the importance/relevance of the computational material being communicated clearly to the students?

7. Are students being asked to reflect on their process, their results, and their own learning during the activity? 
Together, these questions act as a starting point for considering the design of activities and coursework from a computational apprenticeship approach. Once each of these questions is addressed, the five dimensions of the framework can be used to guide the development of the learning design. Future implementations of computational apprenticeship-based learning in a variety of settings will help to both solidify the framework moving forward and assess which dimensions of the framework are most important to emphasize in different contexts.

\section{New Research Directions}

The computational apprenticeship framework has implications for new research directions in the computational education space. To meet growing requirements for computationally trained scientists and engineers, key stakeholders including the National Academies of Sciences, Engineering, and Medicine ([NASEM], 2012), have called for studies on collaborative learning where students generate meaning by interacting in groups that share a common interest (Lave \& Wenger, 1991), or through cognitive apprenticeships, where tacit processes are delivered explicitly (Collins, Brown, \& Holum, 1991). By emphasizing the importance of the classroom learning environment and foregrounding contextual and sociological considerations in the study of computational thinking, computational apprenticeship offers a framework for integrating these important lines of research and shifting computational thinking from a field that is still highly definitional in nature to one that is focused on classroom implementation. In this vein, greater study is needed of specific implementations of computational apprenticeship within higher education contexts.

Research methods such as design-based research and case study are two ways in which computational apprenticeships and computing education can be investigated within the classroom (DBRC, 2003; Yin, 2009). Conducting practitioner research through both design-based research and case study allows researchers to both build computational pedagogy and study the application of computational apprenticeship within the classroom. A current limitation of empirical studies of computational thinking has been difficulty in measuring and assessing computational thinking. Existing methods for assessing computational thinking are limited to taxonomies (Malyn-Smith \& Lee, 2012; Weintrop et al., 2016), and computational thinking knowledge tests that focus heavily on programming knowledge (Peteranetz, Flanigan, Shell, \& Soh, 2017; Shell \& Soh, 2013). The development of standardized rubrics and tests that can assess specific components of computational thinking are critical for supporting empirical study of the effectiveness of the computational apprenticeship framework.

Additionally, longitudinal studies on the effects of implementing computational apprenticeship pedagogy over the course of multiple years are critical for understanding the cumulative effects of these experiences on student outcomes. Forms of pedagogy such as spiral curriculum are reported as being useful for integrating skills such as computational modeling and simulation into the classroom (Magana \& Silva Coutinho, 2017). Understanding not only how computational apprenticeship can be used in a specific class or instructional unit but over an entire undergraduate curriculum is needed to fully investigate the impact this framework has in developing computational thinking 
skills. The scope should not be limited to only undergraduate years, as these highly needed professional skills need studied in professional and continuing education contexts. Thus, there is a need to understand how these skills develop all the way through the undergraduate years and even into graduate coursework and professional years.

The presence of persistent racial, gender, and socioeconomic disparities in participation remain critical challenges for computer science and computational disciplines (Ladner \& Israel, 2016; Michell, Szorenyi, Falkner, \& Szabo, 2017; Scott, McAlear, Martin, \& Koshy, 2017). Using cognitive apprenticeship within computing courses has been shown to significantly lower drop-out rates (Vihavainen, Paksula, \& Luukkainen, 2011). The computational apprenticeship framework offers a constructivist perspective on understanding and addressing these issues. For example, several studies have demonstrated that scaffolding computing instruction within authentic problem-solving contexts can support underrepresented groups interest and achievement in computing (Goode \& Margolis, 2011; Kafai, Searle, Martinez, \& Brayboy, 2014; Yardi \& Bruckman, 2007). Additionally, seminal work at Harvey Mudd College has shown that interventions to change the social dimensions of the learning experience, such as splitting up students by experience level and interest, are critical for producing environments conducive to broader participation in computing (Alvarado, Dodds, \& Libeskind-Hadas, 2012).

The social coding movement has produced jupyter notebooks and other technological platform innovations which can be used to support computational apprenticeship in classroom and workforce settings. For example, free web services such as Google Collaboratory or Glowscript provide browser-based coding environments, which can lower initial barriers to programming. These platforms can facilitate the use of instructional approaches such as 'fill-in-the-blank' and 'use-modify-create' (Lee et al., 2011) that integrate sequencing into computational lessons. Additionally, the ability to comment and embed rich text can help to make observable the heuristics and other metacognitive processes employed by experts during computational problem-solving processes. Foregrounding these metacognitive processes may be particularly beneficial to students from lower socioeconomic backgrounds who may have less opportunity to participate in natural computational apprenticeships in industry internships or through observation from their own social network. 


\section{References}

[NRC]. (2011). Report of a Workshop on the Pedagogical Aspects of Computational Thinking. Washington, D.C.: National Academies Press. https://doi.org/10.17226/13170

[NRC]. (2013). Next Generation Science Standards: For States, By States. Washington, D.C.: The National Academies Press. https://doi.org/https://doi.org/10.17226/18290

[USOPS]. (2016). Fact Sheet: President Obama Announces Computer Science for All Initiative. Retrieved from https://obamawhitehouse.archives.gov/the-pressoffice/2016/01/30/fact-sheet-president-obama-announces-computer-science-allinitiative-0

Alvarado, C., Dodds, Z., \& Libeskind-Hadas, R. (2012). Women 's Participation in Computing at Harvey Mudd College, 3(4), 55-64.

Amalia, F. R., Ibnu, S., Widarti, H. R., \& Wuni, H. (2018). Students' mental models of acid and base concepts taught using the cognitive apprenticeship learning model. Jurnal Pendidikan IPA Indonesia, 7(2), 187-192. https://doi.org/10.15294/jpii.v7i2.14264

Ben-Ari, M. (1998). Constructivism in computer science education. ACM SIGCSE Bulletin, 30(1), 257-261. https://doi.org/10.1145/274790.274308

Bohle Carbonell, K., Stalmeijer, R. E., Könings, K. D., Segers, M., \& van Merriënboer, J. J. G. (2014). How experts deal with novel situations: A review of adaptive expertise. Educational Research Review, 12, 14-29. https://doi.org/10.1016/j.edurev.2014.03.001

Bransford, J. D., Brown, A. L., \& Cocking, R. R. (2000). How People Learn. Washington, D.C.: National Academiy Press.

Buitrago Flórez, F., Casallas, R., Hernández, M., Reyes, A., Restrepo, S., \& Danies, G. (2017). Changing a Generation's Way of Thinking: Teaching Computational Thinking Through Programming. Review of Educational Research, 87(4), 834-860. https://doi.org/10.3102/0034654317710096

Butler, M., \& Morgan, M. (2007). Learning challenges faced by novice programming students studying high level ... ASCILITE - Australian Society for Computers in Learning in Tertiary Education..., 2007(1), 99-107. Retrieved from https://www.learntechlib.org/p/46043/ 
Choi, J., \& Hannafin, M. (1995). Situated cognition and learning environments. Educational Technology Research and Development, 43(2), 53-69.

CollegeBoard. (2013). The College Board AP ® Computer Science Principles Draft Curriculum Framework August 2013. Report, (August), 1-30.

Collins, A. (2006). Cognitive apprenticeship. In R. K. Sawyer (Ed.), The Cambridge Handbook of the Learning Sciences (pp. 47-60). Cambridge: Cambridge University Press. https://doi.org/10.1017/CBO9781139519526.008

Collins, A., Brown, J. S., Newman, S. E., Scardamalia, M., Fischer, F., Resnick, L., ... Rubin, A. (1987). Cognitive Apprenticeship: Teaching the Craft of Reading, Writing, and Mathematics. Center for the Study of Reading.

Curzon, P., Dorling, M., Selby, C., \& Woollard, J. (2014). Developing computational thinking in the classroom: a framework. Computing at School, (June). Retrieved from http://eprints.soton.ac.uk/369594/10/DevelopingComputationalThinkingInTheClassr oomaFramework.pdf

Dane, E. (2010). Reconsidering the trade-off between expertise and flexibility: A cognitive entrenchment perspective. Academy of Management Review, 35(4), 579603. https://doi.org/10.5465/AMR.2010.53502832

Davis, R. S., Parker, K. B., \& Fogle, L. (2019). A Case of Course Revision : Cognitive Apprenticeship and Critical Reflection for ICT in Teacher Preparation, (2006), 1779-1784.

DBRC. (2003). Design-based research: An emerging paradigm for educational inquiry. Educational Researcher, 32(1), 5-8. Retrieved from https://about.jstor.org/terms

Dym, C. L. (2004). Design, Systems, and Engineering Education. International Journal of Engineering Education, 20(3), 305-312.

Feldon, D. F., Shukla, K. D., \& Anne Maher, M. (2016). Faculty-student coauthorship as a means to enhance STEM graduate students' research skills. International Journal for Researcher Development, 7(2), 178-191. https://doi.org/10.1108/ijrd-10-20150027

Gilmore, J., Vieyra, M., Timmerman, B., Feldon, D., \& Maher, M. (2015). The relationship between undergraduate research participation and subsequent research performance of early career STEM graduate students. Journal of Higher Education, 86(6), 834-863. https://doi.org/10.1353/jhe.2015.0031 
Goode, J., \& Margolis, J. (2011). Exploring Computer Science: A case study of school reform. ACM Transactions on Computing Education, 11(2). https://doi.org/10.1145/1993069.1993076

Google. (2015). Computational thinking concepts guide. Retrieved from https://docs.google.com/file/d/0B-E2rcvhnlQ_a1Q4VUxWQ2dtTHM/edit

Grover, S., \& Pea, R. (2013). Computational Thinking in K-12: A Review of the State of the Field. Educational Researcher, 42(1), 38-43. https://doi.org/10.3102/0013189X12463051

Hatano, G., \& Inagaki, K. (1986). Two courses of expertise. In H. Stevenson, H. Azuma, \& K. Hakuta (Eds.), Child Development and Education in Japan (pp. 262-272). New York, NY: W. H. Freeman/Times Books/Henry Holt \& Co.

Hatano, G., \& Oura, Y. (2003). Commentary : Reconceptualizing School Learning. Educational Researcher, 32(8), 26-29. https://doi.org/10.3102/0013189X032008026

Heroux, A. M., \& Allen, G. (2016). Computational Science And Engineering Software Sustainability And Productivity (CSESSP) Challenges Workshop Report. Arglington, VA.

Kafai, Y. B., Searle, K., Martinez, C., \& Brayboy, B. (2014). Ethnocomputing with electronic textiles: Culturally responsive open design to broaden participation in computing in American Indian youth and communities. SIGCSE 2014 - Proceedings of the 45th ACM Technical Symposium on Computer Science Education, (July 2016), 241-246. https://doi.org/10.1145/2538862.2538903

Kalelioğlu, F., Gülbahar, Y., \& Kukul, V. (2016). A Framework for Computational Thinking Based on a Systematic Research Review. Baltic J . Modern Computing, 4(3), 583-596.

Ladner, R. E., \& Israel, M. (2016). Broadening Participation "for All" in "computer Science for All" Seeking to expand inclusiveness in computer science education. Communications of the ACM, 59(9), 26-28. https://doi.org/10.1145/2971329

Lave, J., \& Wenger, E. (1991). Situated learning: Legitimate peripheral participation (Vol. 1991). New York, NY: Cambridge University Press. https://doi.org/10.4135/9781849209823.n11

Lee, I., Martin, F., Denner, J., Coulter, B., Allan, W., Erickson, J., ... Werner, L. (2011). Computational thinking for youth in practice. ACM Inroads, 2(1), 32-37. 
https://doi.org/10.1145/1929887.1929902

Lyons, K., McLaughlin, J. E., Khanova, J., \& Roth, M. T. (2017). Cognitive apprenticeship in health sciences education: a qualitative review. Advances in Health Sciences Education, 22(3), 723-739. https://doi.org/10.1007/s10459-0169707-4

Madamanchi, A., Cardella, M. E., Glazier, J. A., \& Umulis, D. M. (2019). Factors Mediating Learning and Application of Computational Modeling by Life Scientists. Proceedings - Frontiers in Education Conference, FIE, 2018-Octob, 1-5. https://doi.org/10.1109/FIE.2018.8659328

Magana, A. J., Falk, M. L., \& Reese Jr., M. J. (2013). Introducing Discipline-Based Computing in Undergraduate Engineering Education. ACM Transactions on Computing Education, 13(4), 16:1-16:22.

Magana, A. J., Falk, M. L., Vieira, C., \& Reese, M. J. (2016). A case study of undergraduate engineering students' computational literacy and self-beliefs about computing in the context of authentic practices. Computers in Human Behavior, 61, 427-442. https://doi.org/10.1016/j.chb.2016.03.025

Magana, A. J., Fennell, H. W., Vieira, C., \& Falk, M. L. (2019). Characterizing the interplay of cognitive and metacognitive knowledge in computational modeling and simulation practices. Journal of Engineering Education, (February), jee.20264. https://doi.org/10.1002/jee.20264

Magana, A. J., \& Silva Coutinho, G. (2017). Modeling and simulation practices for a computational thinking-enabled engineering workforce. Computer Applications in Engineering Education, 25(1), 62-78. https://doi.org/10.1002/cae.21779

Malyn-Smith, J., \& Lee, I. (2012). Application of the Occupational Analysis of Computational Thinking-Enabled STEM Professionals as a Program Assessment Tool. Journal of Computational Science Education, 3(1), 2-10. Retrieved from http://www.shodor.org/media/content/jocse/volume3/issue1/jocse_volume3_issue1\# page $=8$

Marti, E. J., \& Vegas, L. (2018). Assessing High School Science Teachers' Nature of Engineering ( NOE ) Per- ceptions with an Open-ended NOE Instrument ( Fundamental ) Assessing Secondary Science Teachers ' Nature of Engineering ( NOE ) perceptions with an open-ended NOE instrument The recent adoption of the Next Generation Science Standards ( NGSS ) by some states provides.

Merritt, C., Daniel, M., Munzer, B. W., Nocera, M., Ross, J. C., \& Santen, S. A. (2018). A cognitive apprenticeship-based faculty development intervention for emergency 
medicine educators. Western Journal of Emergency Medicine, 19(1), 198-204. https://doi.org/10.5811/westjem.2017.11.36429

Michell, D., Szorenyi, A., Falkner, K., \& Szabo, C. (2017). Broadening participation not border protection: how universities can support women in computer science. Journal of Higher Education Policy and Management, 39(4), 406-422. https://doi.org/10.1080/1360080X.2017.1330821

Pears, A., Seidman, S., Mannila, L., Malmi, L., Adams, E., Jens, B., ... Paterson, J. (2018). A Survey of Literature on the Teaching of Introductory Programming Arnold, 1846, 161-180. https://doi.org/10.1007/978-1-4939-8712-2_11

Peteranetz, M. S., Flanigan, A. E., Shell, D. F., \& Soh, L. K. (2017). Computational Creativity Exercises: An Avenue for Promoting Learning in Computer Science. IEEE Transactions on Education, 60(4), 305-313. https://doi.org/10.1109/TE.2017.2705152

Peters-Burton, E. E., Merz, S. A., Ramirez, E. M., \& Saroughi, M. (2015). The Effect of Cognitive Apprenticeship-Based Professional Development on Teacher SelfEfficacy of Science Teaching, Motivation, Knowledge Calibration, and Perceptions of Inquiry-Based Teaching. Journal of Science Teacher Education, 26(6), 525-548. https://doi.org/10.1007/s10972-015-9436-1

PITAC. (2005). Computational science: Ensuring America's competitiveness. Arlington, VA: President's Information Technology Advisory Committee. Retrieved from https://www.nitrd.gov/pitac/reports/20050609

Schwartz, D. L., Bransford, J. D., \& Sears, D. (2005). Efficiency in Innovation and Transfer. Transfer of Learning from a Modern Multidisciplinary Perspective, 1-51.

Scott, A., McAlear, F., Martin, A., \& Koshy, S. (2017). Broadening participation in computing: Examining experiences of girls of color. ACM Inroads, 8(4), 48-52. https://doi.org/10.1145/3149921

Shell, D. F., \& Soh, L. K. (2013). Profiles of Motivated Self-Regulation in College Computer Science Courses: Differences in Major versus Required Non-Major Courses. Journal of Science Education and Technology, 22(6), 899-913. https://doi.org/10.1007/s10956-013-9437-9

Subali, E., Rusdiana, D., \& Subali, B. (2017). Development of Cognitive Apprenticeship Instruction Model in Mathematical ... In 1st International Conference on Education.

Thevathayan, C., \& Hamilton, M. (2015). Supporting diverse novice programming 
cohorts through flexible and incremental visual constructivist pathways. In Proceedings of the 2015 ACM Conference on Innovation and Technology in Computer Science Education. ACM.

Vieira, C., Magana, A. J., Roy, A., Falk, M. L., \& Reese, M. J. (2016). Exploring undergraduate students' computational literacy in the context of problem solving. Computers in Education Journal, 16(1), 100-112.

Vieira, C., Roy, A., Magana, A. J., Falk, M. L., \& Reese, M. J. (2016). In-code comments as a self-explanation strategy for computational science education. ASEE Annual Conference and Exposition, Conference Proceedings, 2016-June.

Vihavainen, A., Airaksinen, J., \& Watson, C. (2014). A systematic review of approaches for teaching introductory programming and their influence on success. ICER 2014 Proceedings of the 10th Annual International Conference on International Computing Education Research, (July 2014), 19-26. https://doi.org/10.1145/2632320.2632349

Vihavainen, A., Paksula, M., \& Luukkainen, M. (2011). Extreme apprenticeship method in teaching programming for beginners. SIGCSE'11 - Proceedings of the 42nd ACM Technical Symposium on Computer Science Education, 93-98. https://doi.org/10.1145/1953163.1953196

Weintrop, D., Beheshti, E., Horn, M., Orton, K., Jona, K., Trouille, L., \& Wilensky, U. (2016). Defining Computational Thinking for Mathematics and Science Classrooms. Journal of Science Education and Technology, 25(1), 127-147. https://doi.org/10.1007/s10956-015-9581-5

Yan, J., Vieira, C., \& Magana, A. (2015). Exploring Design Characteristics of Worked Examples to Support Programming and Algorithm Design. The Journal of Computational Science Education, 6(1), 2-15. https://doi.org/10.22369/issn.2153$4136 / 6 / 1 / 1$

Yardi, S., \& Bruckman, A. (2007). What is computing? Bridging the gap between teenagers' perceptions and graduate students' experiences, 39-49.

Yin, R. K. (2009). Case study research: Design \& methods (4th ed.). Thousand Oaks, CA: Sage.

[NASEM]. (2012). Discipline-Based Education Research. Understanding and Improving Learning in Undergraduate Science and Engineering. Washington, D.C.: National Academies Press.

Collins, A., Brown, J. S., \& Holum, A. (1991). Cognitive apprenticeship: Making thinking visible. American educator, 15(3), 6-11. 
Fennell, H., Coutinho, G., Magana, A. J., D, R., \& Zavattieri, P. (2017). Enhancing Student Meaning-Making of Threshold Concepts via Computa-tion: The Case of Mohr's Circle. Computers in Human Behavior, 61. doi:https://doi.org/10.1016/i.chb.2016.03.025

Joseph A. Lyon, A. J. M., Martin R. Okos. (2019). Work in Progress: Designing Modeling-based Learning Experiences Within a Capstone Engineering Course. Paper presented at the 2019 American Society of Engineering Education Conference, Tampa, Fl.

Koretsky, M. D., \& Magana, A. J. (2019). Using Technology to Enhance Learning and Engagement in Engineering. Advances in Engineering Education. Retrieved from http://files.eric.ed.gov/fulltext/EJ1220296.pdf.

Lave, J., \& Wenger, E. (1991). Situated learning: Legitimate pheripherial participation.

Magana, A. J. (2017). Modeling and Simulation in Engineering Education: A Learning Progression. Journal of Professional Issues in Engineering Education and Practice, 143(4), 04017008. Retrieved from https://ascelibrary.org/doi/abs/10.1061/\%28ASCE\%29EI.1943$5541.0000338 \%$ X This study used a Delphi technique to identify relevant modeling and simulation practices required in present-day workplace engineering. Participants consisted of 37 experts divided into two panels: 18 experts in academia on one panel, and 19 experts from industry on another panel. Panel members participated in three rounds of data collection in which they offered their opinions about the relevance of specific modeling and simulation skills, and opinions about when these practices should be introduced into the undergraduate and graduate engineering curricula. The guiding research question was: What are the required modeling and simulation practices to be integrated as part of the engineering curricula at the undergraduate and graduate levels? Findings from this study were used to inform a preliminary learning progression for modeling and simulation in undergraduate and graduate engineering education. Outcomes from this study represent a linchpin for future research about learning and achievement of modeling and simulation practices, which can delineate the nature of productive instructional pathways toward modeling and simulation proficiency. doi:doi:10.1061/(ASCE)El.1943-5541.0000338

Magana, A. J., Brophy, S. P., \& Bodner, G. M. (2012a). Instructors' intended learning outcomes for using computational simulations as learning tools. Journal of Engineering Education, 101(2), 220-243.

Magana, A. J., Brophy, S. P., \& Bodner, G. M. (2012b). Student views of engineering professors technological pedagogical content knowledge for integrating computational simulation tools in nanoscale science and engineering. International Journal of Engineering Education, 28(5), 1033.

Magana, A. J., Falk, M. L., \& Reese Jr, M. J. (2013). Introducing discipline-based computing in undergraduate engineering education. ACM Transactions on Computing Education (TOCE), 13(4), 16.

Magana, A. J., Falk, M. L., Vieira, C., \& Reese Jr, M. J. (2016). A case study of undergraduate engineering students' computational literacy and self-beliefs about computing in the context of authentic practices. Computers in Human Behavior, 61, 427-442.

Magana, A. J., Ortega-Alvarez, J. D., Lovan, R., Pizano, D. G., Marulanda, J., \& Dyke, S. (2017). Virtual, local and remote laboratories for conceptual understanding of dynamic systems. The International journal of engineering education, 33(1), 91-105.

Ortega-Alvarez, J. D., Sanchez, W., \& Magana, A. J. (2018). Exploring Undergraduate Students' Computational Modeling Abilities and Conceptual Understanding of Electric Circuits. IEEE Transactions on Education, 61(3), 204-213. 
Shaikh, U. A., Magana, A. J., Vieira, C., \& Garcia, R. E. (2015). An exploratory study of the role of modeling and simulation in supporting or hindering engineering students' problem solving skills. Paper presented at the Proceedings of the 2015 ASEE Annual Conference and Exposition. Seattle, Washington.

Vieira, C., Magana, A. J., Roy, A., \& Falk, M. L. (2019). Student explanations in the context of computational science and engineering education. Cognition and Instruction, 37(2), 201231.

Vieira, C., Yan, J., \& Magana, A. J. (2015). Exploring design characteristics of worked examples to support programming and algorithm design. Journal of Computational Science Education, 6(1), 2-15. 


\section{Appendices}

Appendix 1.

\begin{tabular}{|c|c|c|}
\hline \multirow{4}{*}{$\begin{array}{l}\text { Disciplinary } \\
\text { Content }\end{array}$} & Domain Knowledge & $\begin{array}{l}\text { Core subject knowledge. Content, } \\
\text { facts, and procedures specific to the } \\
\text { subject. }\end{array}$ \\
\hline & Heuristic Strategies & $\begin{array}{l}\text { Generally effective techniques for } \\
\text { solving problems within the subject } \\
\text { domain (i.e., "tricks of the trade" and } \\
\text { "rules of thumb"). }\end{array}$ \\
\hline & Control Strategies & $\begin{array}{l}\text { Metacognitive strategies for } \\
\text { monitoring progress and degree of } \\
\text { success throughout a task. }\end{array}$ \\
\hline & Learning Strategies & $\begin{array}{l}\text { Strategies for independently acquiring } \\
\text { new content knowledge and } \\
\text { procedural skills within the domain. }\end{array}$ \\
\hline \multirow{4}{*}{$\begin{array}{c}\text { Computational } \\
\text { Content }\end{array}$} & Programming Knowledge & $\begin{array}{l}\text { Knowledge of programming and } \\
\text { general algorithmic design/thinking. } \\
\text { Essential coding skills not specific to a } \\
\text { particular programming language. }\end{array}$ \\
\hline & Computational Methods & $\begin{array}{l}\text { General techniques for solving } \\
\text { problems using computation. Many } \\
\text { computational methods apply to a } \\
\text { variety of disciplinary contexts. }\end{array}$ \\
\hline & Troubleshooting/Debugging & $\begin{array}{l}\text { Strategies for fixing, testing, and } \\
\text { verifying/validating code throughout a } \\
\text { computational task. }\end{array}$ \\
\hline & Learning Strategies & $\begin{array}{l}\text { Strategies for independently acquiring } \\
\text { new computational knowledge and } \\
\text { programming strategies. }\end{array}$ \\
\hline Method & Modeling & $\begin{array}{l}\text { Performance of disciplinary tasks by } \\
\text { an expert practitioner. Externalization } \\
\text { of otherwise internal processes } \\
\text { exposes learners to critical modes of } \\
\text { thinking within the discipline that are } \\
\text { often not made explicit by the content } \\
\text { alone. }\end{array}$ \\
\hline
\end{tabular}




\begin{tabular}{|c|c|c|}
\hline & Coaching & $\begin{array}{l}\text { Monitoring students as they } \\
\text { participate in disciplinary tasks and } \\
\text { offering hints, feedback, and } \\
\text { suggestions in real time. This allows } \\
\text { learners' difficulties to be addressed as } \\
\text { they arise during task performance and } \\
\text { thus while the learning is still } \\
\text { contextually situated. }\end{array}$ \\
\hline & Scaffolding & $\begin{array}{l}\text { Supports provided by the instructional } \\
\text { design to help guide the learning } \\
\text { process. These supports should be } \\
\text { faded out (i.e., gradually removed) } \\
\text { over time as learners become more } \\
\text { adept within the domain. }\end{array}$ \\
\hline & Articulation & $\begin{array}{l}\text { Requiring students to openly explain } \\
\text { their reasoning and problem-solving } \\
\text { processes when engaged in } \\
\text { disciplinary tasks. This helps the } \\
\text { learner characterize their own } \\
\text { approaches to "thinking like an X" and } \\
\text { provides critical information to the } \\
\text { instructors for assessment purposes. }\end{array}$ \\
\hline & Reflection & $\begin{array}{l}\text { Encouraging students to compare their } \\
\text { solution approaches with those of } \\
\text { others in order to evaluate the quality } \\
\text { or "expertness" of their own } \\
\text { approaches. This empowers students } \\
\text { to reorganize and improve their own } \\
\text { thinking as they move closer to } \\
\text { thinking like a computational expert. }\end{array}$ \\
\hline & Exploration & $\begin{array}{l}\text { Encouraging students to develop their } \\
\text { own modes of thinking and problem- } \\
\text { solving within the discipline on their } \\
\text { own. Some level of self-directed } \\
\text { learning is critical in the development } \\
\text { of learning strategies within a domain. }\end{array}$ \\
\hline Sequencing & Increasing Complexity & $\begin{array}{l}\text { Structuring tasks from simpler to } \\
\text { more complex so that more skills are } \\
\text { needed to address subsequent } \\
\text { problem as the learner progresses } \\
\text { through activities. }\end{array}$ \\
\hline
\end{tabular}




\begin{tabular}{|c|c|c|}
\hline & Increasing Diversity & $\begin{array}{l}\text { Structuring tasks from narrow to } \\
\text { broad so that a wider variety and } \\
\text { intersection of skills is needed to } \\
\text { address problems later in the } \\
\text { curriculum. }\end{array}$ \\
\hline & Global to Local & $\begin{array}{l}\text { Introducing learners to the general } \\
\text { skills needed to approach whole } \\
\text { problems before focusing in on the } \\
\text { procedural details of solving } \\
\text { individual components of the } \\
\text { problem. }\end{array}$ \\
\hline \multirow{4}{*}{ Sociology } & Situated Learning & $\begin{array}{l}\text { Designing instructional tasks that } \\
\text { reflect the nature of analogous real- } \\
\text { world tasks. Learning activities should } \\
\text { be authentic in the sense that they } \\
\text { mimic the complexity and tone of real } \\
\text { disciplinary problems within a } \\
\text { controlled learning environment. }\end{array}$ \\
\hline & Distributed Community & $\begin{array}{l}\text { The creation of a learning } \\
\text { environment in which learners are } \\
\text { encouraged to actively communicate } \\
\text { with experts and peers about their own } \\
\text { experience and learning. Uniquely } \\
\text { facilitated in computation through } \\
\text { online resources, knowledge bases, } \\
\text { and troubleshooting communities. }\end{array}$ \\
\hline & Intrinsic Motivation & $\begin{array}{l}\text { Creating educational environments } \\
\text { and learning activities that engage } \\
\text { students through their own interest in } \\
\text { the material, rather than external, } \\
\text { performative motivations such as good } \\
\text { grades. }\end{array}$ \\
\hline & Global Cooperation & $\begin{array}{l}\text { Designing learning activities that } \\
\text { encourage cooperative problem- } \\
\text { solving. Extends learning resources } \\
\text { through online and offline peer } \\
\text { connections and is critical to } \\
\text { establishing a community of practice. }\end{array}$ \\
\hline
\end{tabular}

